\title{
Experimental Study of SXES: Determination of Iron Oxidation State in Silicate Minerals
}

Takaomi Yokoyama ${ }^{1}$, Shogo Koshiya ${ }^{1}$, Kenichi Tsutsumi ${ }^{1}$, Terumi Ejima ${ }^{2}$ and Yoshiaki Kon ${ }^{3}$

${ }^{1}$ JEOL Ltd., Akishima, Tokyo, Japan, ${ }^{2}$ Shinshu University, Matsumoto, Nagano, Japan, ${ }^{3}$ National Institute of Advanced Industrial Science and Technology (AIST), Tsukuba, Ibaraki, Japan

Determination technique of Fe oxidation state in silicate minerals using electron probe micro analysis (EPMA) has been investigated since the 1970's. The technique based either change of the intensity or the wavelength of soft X-ray emission lines. Albee \& Chodos (1970) ${ }^{1}$ reported that relative intensity of Fe $L \alpha$ and $L \beta \mathrm{X}$-ray emission peaks measured by EPMA differ based on valence state and bond association. This method has recognized to useful to Fe oxides and some silicates ${ }^{1,2,3}$. Höfer et al., $(1994,2000)$ was established the method that exploits a concomitant change of both the intensity and wavelength of the $\mathrm{Fe}$ $L$-emission ${ }^{4,5}$. Currently, this "flank method" is available for determination of Fe oxidation states of Fe oxide, pyroxenes and garnets 6,7 .

Soft X-ray emission spectrometer (SXES) is same as wavelength dispersive spectrometer in terms of measuring electron beam induced X-ray by wavelength dispersion, on the other hands, SXES uses static varied-line-spacing grating for dispersion of soft X-ray ${ }^{8}$. The usage of SXES to probe solid state effect, the energy state of bonding electrons ${ }^{8,9}$. We studied fitting method for measured spectra and estimation of self-absorption effect to quantitative evaluation of intensity and energy of Fe $L$-emission.

Calibration energy set to $705.0 \mathrm{eV}$ on the Fe $L \alpha$ peak top of metallic iron standard. Iron oxide samples $\left(\mathrm{FeO}, \mathrm{Fe}_{3} \mathrm{O}_{4}\right.$ and $\mathrm{Fe}_{2} \mathrm{O}_{3}$ ) were measured as follow up to previous studies. The silicate samples are fayalite $\left(\mathrm{Fe}_{2} \mathrm{SiO}_{4}\right)$, almandine $\left(\mathrm{Fe}_{3} \mathrm{Al}_{2}\left(\mathrm{SiO}_{4}\right)_{3}\right)$, hedenbergite $\left(\mathrm{CaFeSi}_{2} \mathrm{O}_{6}\right)$, andradite $\left(\mathrm{Ca}_{3} \mathrm{Fe}_{2}\left(\mathrm{SiO}_{4}\right)_{3}\right)$ and some natural silicate minerals available Fe oxidation number obtained by wet analysis and Mössbauer spectroscopy. Fe L-emission spectra was measured by soft X-ray emission spectrometer (SS94040SXSER, JEOL) paired with field emission electron probe microanalyzer (JXA-8530FPlus, JEOL). Grating was JS2000 (energy dispersive range: 100-2300 eV, energy resolution: $5.0 \mathrm{eV}$ at FWHM of Fe $L \alpha)$.

Measured peaks of Fe $L$-emission spectra are fitting by least-square method using pseudo-Voigt function. Background intensities approximating by linear function. Large and systematic residue appeared between measured spectra and fitting lines when using 2 components for Fe $L \alpha$ and $L \beta$ peak (Fig.1a). Fitting calculation using 3components ( 2 for $\mathrm{Fe} L \alpha$ and another 1 for $L \beta$ ) reduced obviously residual errors from the measured spectra of Fe oxide and silicates (Fig. 1b). This is thought to be due to splitting of energies of Fe $d$ orbitals result of bonding with neighboring $\mathrm{O}$.

Self-absorption effect usually affect to emission spectra from taken at different accelerating voltages. Höfer et al. $(1994,2007)^{2,4}$ proposed determination method of self-absorption spectra for EPMA measurement. However, these calculations are normalizing different peaks at flank position of Fe $L \alpha$ or $L \beta$, this induces incorrect peak shift of self-absorption spectra. We modified this normalization as have unified height of Fe $L \alpha$ peaks to comparing self-absorption effect from changing the shape of spectra (Fig. 2). 
We will discuss determination method of oxidation states iron in different silicate minerals using Fe $L$ emission spectra acquired by SXES, and report some result of natural mineral samples.
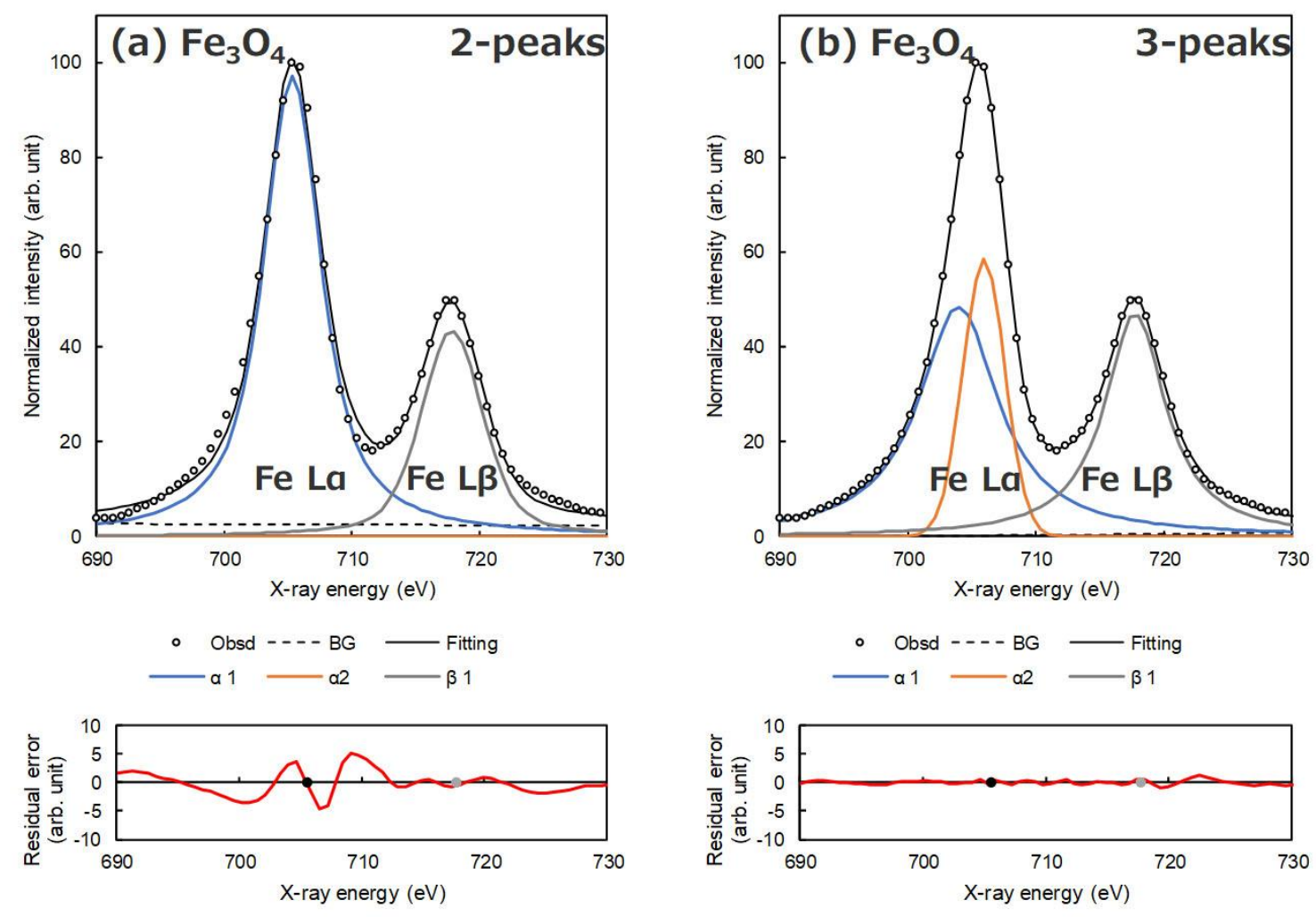

- Residual - a peak - $\beta$ peak

- Residual - a peak $-\beta$ peak

Figure 1. Measured Fe L-emission spectra of magnetite (Fe3O4) and fitting functions. Graphs below are residual error of fitting line from measured spectra. 

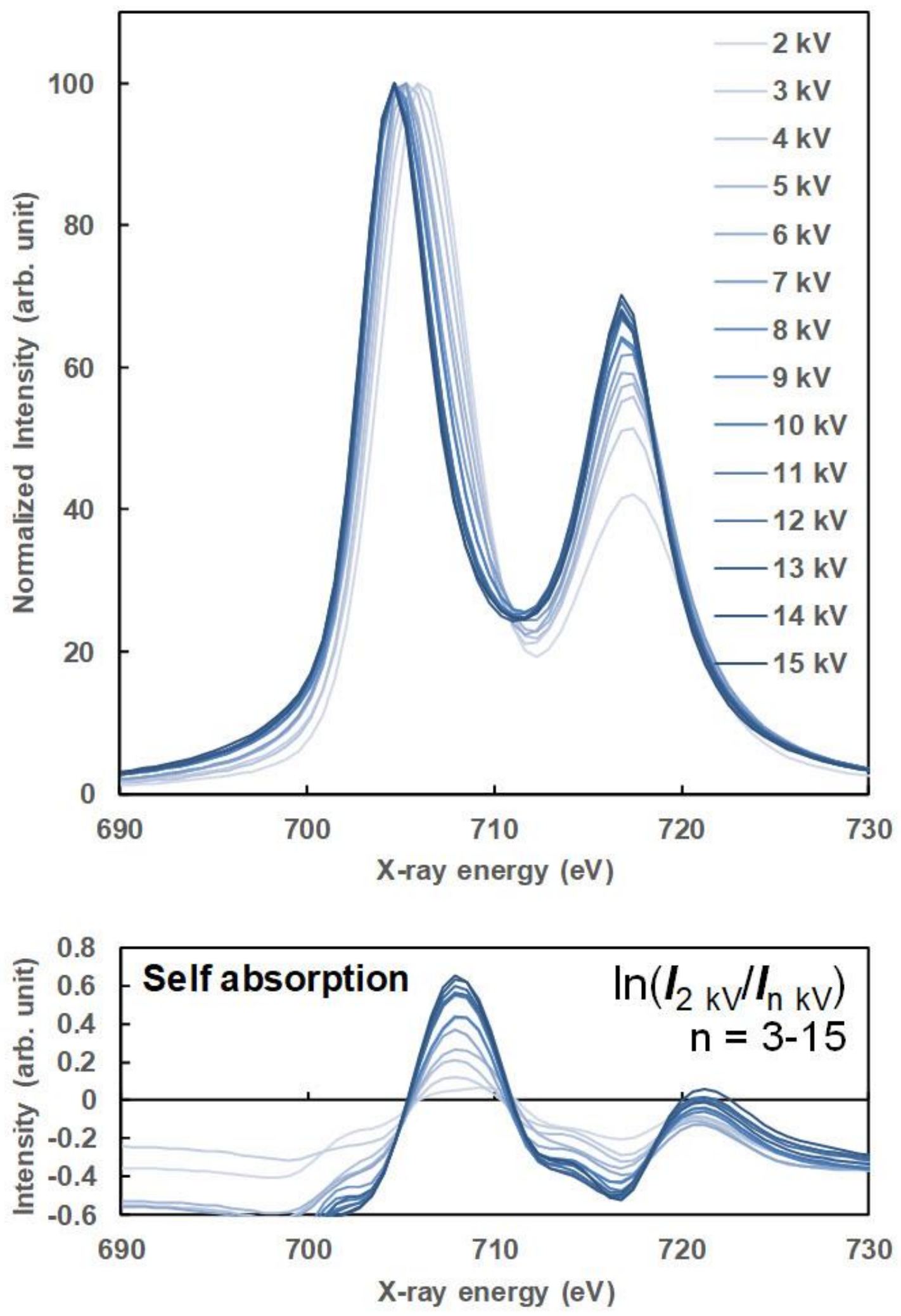

Figure 2. Fe L-emission spectra of almandine (Fe3Al2(SiO4)3) at 2 to $15 \mathrm{kV}$ and calculated selfabsorption spectra. 
References

1. Albee, A. L. \& Chodos, A. Mineral. J. Earth Planet. Mater. 55, 491-501 (1970)

2. Lamb, M. W. et al. Min. 97, 951-961 (2012)

3. T. et al. J. Mineral. Petrol. Sci. 108, 25-36 (2013)

4. Höfer, H. E. et al. J. Mineral. 6, 407-418 (1994)

5. Höfer, H. E. et al. J. Mineral. 12, 63-71 (2000)

6. Höfer, H. E. \& Brey, G. P. Mineral. 92, 873-885 (2007)

7. Borfecchia, E. et al. Anal. At. Spectrom. 27, 1725-1733 (2012)

8. Takahashi, H. et al. IOC Conf. Ser. Mater. Sci. Eng. 109, 012017 (11 pages) (2016)

9. Takahashi, H. et al. EMAS 2017 Proceedings. 458-459 (2017) 